\title{
Editorial Message: Special Issue on Fuzzy Systems in Intelligent Systems and Applications
}

\author{
Huchang Liao $^{1}$ - Abbas Mardani ${ }^{2} \cdot$ Edmundas Kazimieras Zavadskas $^{3} \cdot$ \\ Benjamin Bedregal ${ }^{4}$
}

Published online: 10 March 2020

(C) Taiwan Fuzzy Systems Association 2020

As the guest editors of the special issue on Fuzzy Systems in Intelligent Systems and Applications, we would like to publish the latest, innovative, and outstanding research results in the International Journal of Fuzzy Systems $(I J F S)$. Fuzzy system in intelligent systems and applications is an interdisciplinary area focusing upon methodologies for extracting useful intelligent systems and its applications. It has received growing attention in solving real-world problems regarding various fields such as bioinformatics, business and finance, intelligent decision support systems, database systems, e-learning, e-administration, environmental engineering, healthcare, security, sensors, automation, mobile robotics, manufacturing systems, infrastructure and transportation, and so on.

The call for papers of this special issue was during March 2019-August 2019. The objective of this special issue is to explore the evolving research with regard to the tools, techniques, and applications of broadly perceived fuzzy systems in intelligent systems. Totally 16 papers

Huchang Liao

liaohuchang@163.com

Abbas Mardani

abbasmardani@usf.edu

Edmundas Kazimieras Zavadskas

edmundas.zavadskas@vgtu.lt

Benjamin Bedregal

bedregal@dimap.ufrn.br

Sichuan University, Chengdu, China

2 University of South Florida, Tampa, USA

3 Vilnius Gediminas Technical University, Vilnius, Lithuania

4 Federal University of Rio Grande do Norte, Porto Alegre, Brazil were selected for publication in this IJFS special issue according to the review criterion on technical contributions and asked for quality improvements according to the reviewers' comments. These papers provide interesting and up-to-date innovative results covering intelligent fuzzy systems such as the multidimension- and function-adaptive network-based fuzzy inference system, adaptive simulated annealing particle swarm optimization (SAPSO) algorithm to optimize the fuzzy controller, and general framework of type-1 membership function construction, intelligent system applications such as the evaluation model of industrial operation quality, the performance optimization of cyber physical wireless body area networks, the evaluation of the performance of search and rescue robots and the e-government web site evaluation, decision-making models used in different contexts such as the multi-granular unbalanced hesitant fuzzy linguistic term sets, intertemporal hesitant fuzzy soft sets, neutrosophic soft sets, intuitionistic uncertain linguistic decision-theoretic rough sets, hesitant fuzzy multiple integrals and evidential reasoning algorithm, and the supply chain management with intelligent fuzzy tools such as the integrated fuzzy carbon management-based model, fuzzy associative memory modeling, and extended Pythagorean fuzzy TOPSIS method. These papers bring a rich collection on fuzzy systems in intelligent systems and applications.

As the guest editors of this special issue, we would like to acknowledge all the contributors to this special issue. 